\title{
Enrichment of herpes simplex virus type 2 (HSV-2) reactive mucosal Tcells in the human female genital tract
}

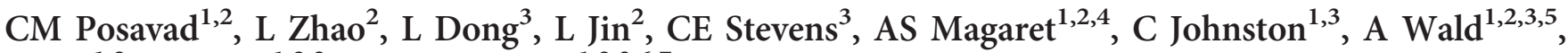 \\ $\mathrm{J}_{\mathrm{Zhu}}{ }^{1,2}, \mathrm{~L}_{\text {Corey }}{ }^{1,2,3}$ and DM Koelle ${ }^{1,2,3,6,7}$
}

Local mucosal cellular immunity is critical in providing protection from HSV-2. To characterize and quantify HSV-2reactive mucosal Tcells, lymphocytes were isolated from endocervical cytobrush and biopsy specimens from $17 \mathrm{HSV}-2$ infected women and examined ex vivo for the expression of markers associated with maturation and tissue residency and for functional T-cell responses to HSV-2. Compared with their circulating counterparts, cervix-derived CD4 + and CD8 + T cells were predominantly effector memory T cells (CCR7 - /CD45RA - ) and the majority expressed CD69, a marker of tissue residency. Co-expression of CD103, another marker of tissue residency, was highest on cervix-derived CD8 + T cells. Functional HSV-2 reactive CD4 + and CD8 + T-cell responses were detected in cervical samples and a median of $17 \%$ co-expressed CD103. HSV-2-reactive CD4 + Tcells co-expressed IL-2 and were significantly enriched in the cervix compared with blood. This first direct ex vivo documentation of local enrichment of HSV-2-reactive Tcells in the human female genital mucosa is consistent with the presence of antigen-specific tissue-resident memory Tcells. Ex vivo analysis of these T cells may uncover tissue-specific mechanisms of local control of HSV-2 to assist the development of vaccine strategies that target protective T cells to sites of HSV-2 infection.

\section{INTRODUCTION}

HSV-2 is one of the most common sexually transmitted infections worldwide, is the major cause of genital ulcer disease, and causes an incurable, lifelong infection. HSV-2 infection increases the risk of HIV acquisition. ${ }^{1} \mathrm{HSV}-2$ reactivation and shedding still occur in persons taking antiviral therapy. ${ }^{2}$ The development of prophylactic and therapeutic vaccines for HSV-2 infection has been challenging with several failures for prophylactic vaccines and limited success for immunotherapy. ${ }^{3-5}$

Because HSV-2 is acquired at mucosal surfaces, local T cells are relevant to initial viral replication and subsequent pathogenesis. Murine studies have elucidated many aspects of local T-cell immunity to HSV-2 including trafficking of $T$ cells to sites of active infection, persistence of T cells at sites of prior HSV-2 exposure, effector mechanisms, and vaccine strategies that target $\mathrm{T}$ cells to sites of HSV-2 exposure. ${ }^{6-8}$ However, the data obtained in animal models of HSV-2 and other pathogens have been difficult to translate to the natural human host. Intravaginal inoculation of HSV kills mice acutely via ascending neurologic or autonomic infection and surviving mice do not spontaneously recur, ${ }^{9,10}$ while humans are seldom killed by primary infection and almost all HSV-2-infected persons have recurrent shedding from the genital tract. ${ }^{11}$ In the present study, we seek to confirm and extend animal data in immunocompetent women.

Although numerous studies characterize the T-cell response to HSV in human blood, skin, ganglia, and eye (reviewed in ref. 12), the female reproductive tract (FRT) has received less attention. We detected HSV-2-reactive T-cell responses in the human female uterine cervix by nonspecific in vitro polyclonal T-cell expansion and demonstrated responses during both

${ }^{1}$ Vaccine and Infectious Disease Division, Fred Hutchinson Cancer Research Center, Seattle, Washington, USA. ${ }^{2}$ Department of Laboratory Medicine, University of Washington, Seattle, Washington, USA. ${ }^{3}$ Department of Medicine, University of Washington, Seattle, Washington, USA. ${ }^{4}$ Department of Biostatistics, University of Washington, Seattle, Washington, USA. ${ }^{5}$ Department of Epidemiology, University of Washington, Seattle, Washington, USA. ${ }^{6}$ Department of Global Health, University of Washington, Seattle, Washington, USA and ${ }^{7}$ Benaroya Research Institute, Seattle, Washington, USA. Correspondence: CM Posavad (posavad@uw.edu) 
lesional and non-lesional time periods, persisting during suppressive antiviral therapy. ${ }^{13}$ Recently, we extended these findings and showed the frequent and persistent detection of HSV-2-reactive $\mathrm{T}$ cells from cervical cytobrush specimens collected from HSV-2-infected women that were predominantly $\mathrm{CD} 4+$ and directed at a broad range of HSV-2 proteins. ${ }^{14}$ These data suggest that T-cell responses to HSV-2 are resident at mucosal sites of HSV-2 infection and may be involved in limiting the clinical consequences of secondary HSV-2 infection from endogenous reactivation or exogenous reinfection. ${ }^{13,14}$

Ex vivo analysis of these cells allows unbiased characterization of the cellular composition, function, and phenotype of the local T-cell response to HSV-2. In the present study, we obtained cervical samples by cytobrush and biopsy methods to better characterize HSV-2-reactive T cells present in the FRT in the context of the total FRT T-cell population.

\section{RESULTS}

\section{Subjects and specimens}

We studied 17 HSV-2 seropositive women; of these, 6 were coinfected with HSV-1 (Table 1). The median age of the women was 39 years (range $22-68$ years) and most were white (88.2\%). The participants had reported symptomatic genital HSV-2 infection for a median of 11 years (range 1.1-40.8 years). We

\section{Table 1 Study participants and cervical samples}

\begin{tabular}{|c|c|c|c|c|c|c|}
\hline \multirow[t]{2}{*}{ ID } & \multirow{2}{*}{$\begin{array}{c}\text { Age } \\
\text { (years) }^{a}\end{array}$} & \multirow{2}{*}{$\begin{array}{l}\text { Time since 1st } \\
\text { episode } \mathrm{e}^{\mathrm{b}}\end{array}$} & \multirow{2}{*}{$\begin{array}{c}\text { HSV } \\
\text { serostatus }\end{array}$} & \multirow[t]{2}{*}{ Race } & \multicolumn{2}{|c|}{ Cervical sample (\#) } \\
\hline & & & & & Cytobrush & Biopsy \\
\hline 1 & 51.6 & 27.8 & $1-/ 2+$ & White & 1 & 1 \\
\hline 2 & 67.7 & 40.8 & $1+/ 2+$ & White & 1 & 1 \\
\hline 3 & 39.9 & 11.0 & $1-/ 2+$ & White & 1 & 1 \\
\hline 4 & 50.5 & 34.3 & $1-/ 2+$ & Black & 1 & 0 \\
\hline 5 & 38.8 & 8.8 & $1-/ 2+$ & White & 1 & 0 \\
\hline 6 & 29.0 & 8.6 & $1+/ 2+$ & White & 1 & 0 \\
\hline 7 & 23.6 & 3.1 & $1-/ 2+$ & White & 1 & 1 \\
\hline 8 & 30.8 & 16.4 & $1-/ 2+$ & White & 1 & 1 \\
\hline 9 & 32.9 & 3.7 & $1-/ 2+$ & White & 1 & 0 \\
\hline 10 & 22.0 & 1.5 & $1-/ 2+$ & Black & 1 & 0 \\
\hline 11 & 51.0 & 18.0 & $1-/ 2+$ & White & 0 & 1 \\
\hline 12 & 56.4 & 5 & $1+/ 2+$ & White & 0 & 1 \\
\hline 13 & 63.5 & 18.9 & $1+/ 2+$ & White & 0 & 1 \\
\hline 14 & 27.7 & 3.5 & $1+/ 2+$ & White & 0 & 1 \\
\hline 15 & 45.0 & 14.0 & $1+/ 2+$ & White & 1 & 1 \\
\hline 16 & 38.3 & 19.6 & $1-/ 2+$ & White & 0 & 1 \\
\hline 17 & 37.0 & 1.1 & $1-/ 2+$ & White & 0 & 1 \\
\hline 18 & 26.0 & $N A^{c}$ & $1-/ 2-$ & White & 1 & 0 \\
\hline 19 & 51.0 & NA & $1-/ 2-$ & White & 1 & 0 \\
\hline
\end{tabular}

${ }^{\mathrm{a} A g e}$ is at time of sampling.

bTime since first episode of symptomatic genital herpes. Not applicable. also enrolled two women who were HSV-1 and -2 seronegative (HSVneg) with a median age of 39 years (26 and 51 years) and both were white. We studied 11 cytobrush samples and 12 cervical biopsies from the HSV-2-infected participants and two cytobrush samples from the HSVneg women. From six of the HSV-2-infected participants, we received both cervical samples. All the HSV-2-infected participants were asymptomatic when the specimens were collected. We obtained a cervicovaginal lavage (CVL) sample from 14 of the 17 HSV-2infected women, and from both the HSVneg women at the same visit we obtained other mucosal samples and all CVL samples were negative for HSV DNA.

\section{Quantification and phenotype of total CD3 + T cells}

Total $\mathrm{T}$ cells isolated from peripheral blood mononuclear cells (PBMCs), cervical cytobrushes and biopsies were phenotyped by flow cytometry. The gating strategy is depicted for a representative PBMC and biopsy sample (Figure 1a) and from a representative cervical cytobrush (Supplementary Figure 1A online). Cervical biopsies yielded significantly more total CD3 + cells compared with cervical cytobrush samples. The median total yield of $\mathrm{CD} 3+$ cells from the 12 cervical biopsies was 8,421 (range 3,234-81,845 cells) compared with a median of 1,908 (range 972-12,117 cells) from the 11 cervical cytobrush samples $(P=0.0011$; Figure 1b left). Total CD3 + cells from cytobrushes comprised predominantly CD4 $+\mathrm{T}$ cells with a median of $71.1 \%$ CD4 + (range 40-78.3\%) and $21.8 \%$ CD8 + cells (range 9.7-40.6\%; $P=0.0033$ comparing the proportion of CD $4+$ vs. CD $8+$ T cells; Figure $1 \mathbf{b}$ right). In contrast, $\mathrm{CD} 3+\mathrm{T}$ cells from biopsies were more balanced in their composition of CD4 + and CD8 + T cells: CD $3+$ cells from biopsies were comprised of a median of $45.6 \% \mathrm{CD} 4+$ (range 25.9-65.9\%) and 43.8\% CD8 + cells (range 29.7-72.7\%; $P=0.78$; Figure $1 \mathbf{b}$ right).

The maturational profile of $\mathrm{CD} 4+$ and $\mathrm{CD} 8+\mathrm{T}$ cells from PBMC and cervical samples was assessed using surface CCR7 and CD45RA levels. Although models of memory T-cell subsets, commitment, and plasticity continue to evolve, these markers (Figure 1a, right) provide a useful framework for progression of $\mathrm{T}$ cells from naive to terminally differentiated effector cells. ${ }^{15}$ Representative paired dotplots (Figure 1a) and summarized data (Figure 1c) show that total CD4 $+\mathrm{T}$ cells isolated from cervical biopsies were predominantly effector memory $\mathrm{T}$ cells $\left(\mathrm{T}_{\mathrm{EM}}\right.$; CCR7 - /CD45RA - ) with much lower percentages of central memory $\left(\mathrm{T}_{\mathrm{CM}}\right.$; CCR7 $+/ \mathrm{CD} 45 \mathrm{RA}-$ ), naive (CCR7 + /CD45RA +), and T CD45RA + ). Similarly, total CD8 $+\mathrm{T}$ cells isolated from cervical biopsies were predominantly $\mathrm{T}_{\mathrm{EM}}$ (Figure 1a and c). The predominance of $\mathrm{T}_{\mathrm{EM}}(\mathrm{CCR} 7-/ \mathrm{CD} 45 \mathrm{RA}-)$ in total $\mathrm{CD} 4+$ and $\mathrm{CD} 8+\mathrm{T}$ cells was observed in three cytobrush samples from which we had sufficient cells for analysis (Supplementary Figure 1A). In contrast, PBMC-derived $\mathrm{CD} 4+\mathrm{T}$ cells were comprised of a broad mixture of $\mathrm{T}_{\mathrm{CM}}$, $\mathrm{T}_{\mathrm{EM}}$, and naive cells while PBMC-derived CD8 $+\mathrm{T}$ cells contained all four phenotypes (representative data, Figure 1a, top right). Summarized data (Figure 1c) from $7 \mathrm{HSV}-2+$ 
a

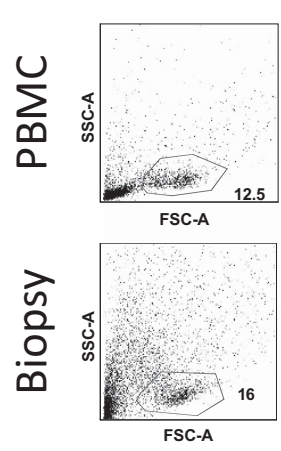

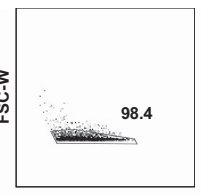

FSC-H

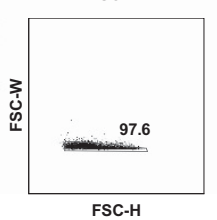

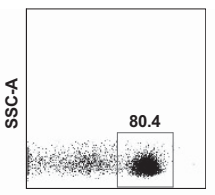

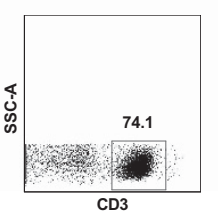

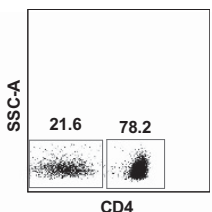

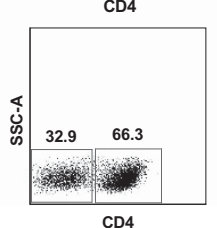

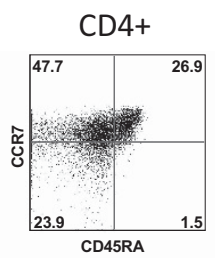

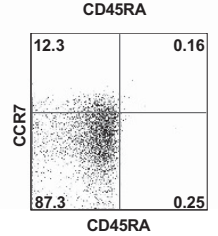

$\mathrm{CD} 8+(\mathrm{CD} 3+/ \mathrm{CD} 4-)$
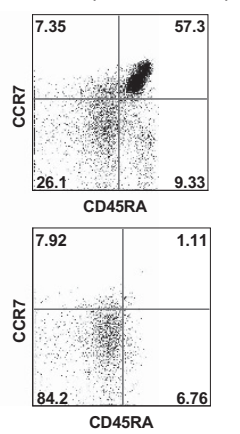

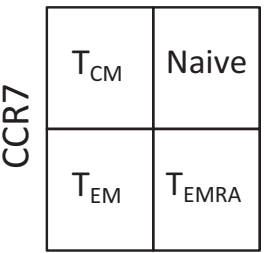

CD45RA b

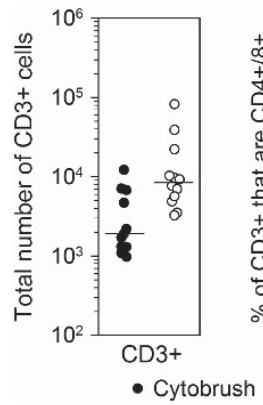

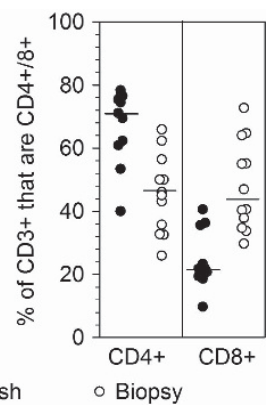
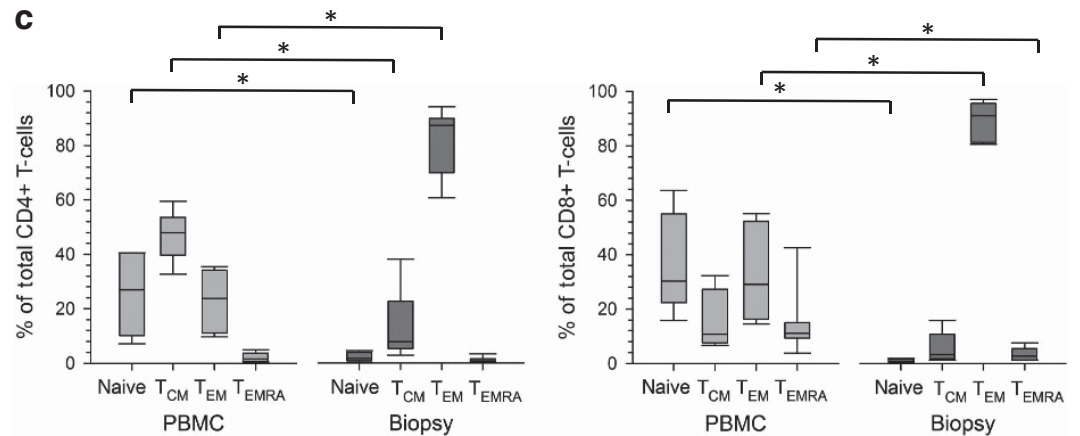

Figure 1 Phenotype of T cells isolated from cervix and PBMCs. (a) Representative flow cytometry gating strategy for the enumeration of T cell subsets. The cells isolated from PBMCs (top row of graphs) and a cervical biopsy (bottom row of graphs) from a representative participant were gated on lymphocytes, singlets, live cells, CD3 + cells, and finally CD4 + and CD8 + (CD3 + /CD4 - ) cells. The expression of CCR7 and CD45RA was analyzed on total CD4 + and total CD8 + (CD3 + /CD4 - ) cells and gated as quadrants. The box at the right labels quadrants. ${ }^{15}$ (b) Yield and T-cell subset composition of CD3 + T cells from cervical samples. The cells were isolated from cytobrush (closed circles) or biopsy (open circles) samples and enumerated for the total number of CD3 + cells (left graph). The \% of the total CD3 + cells that are CD4 + or CD8 + (CD3 + /CD4 - ) is displayed in the right graph. Medians are presented as bars. (c) Cervix-derived CD4 + and CD8 + T cells are predominantly $\mathrm{T}_{\mathrm{EM}}$. Percentage contribution of each T-cell population to the total CD4 + (left) or CD8 + (right) T-cell subset from PBMC or cervical biopsy is displayed from HSV-2-infected participants $(n=7)$. Each box displays the median, 25th and 75th percentiles and error bars display the 10th and 90th percentiles. ${ }^{\star} P=0.018$.

participants show the median proportions of $\mathrm{T}_{\mathrm{EM}}$ for both $\mathrm{CD} 4+$ and CD8 + T-cell subsets were significantly greater for cervix (medians $87.3 \%$ and $90.9 \%$ for CD $4+$ and CD8 + T cells, respectively) compared with blood (medians $23.8 \%$ and $29.1 \%$ for CD $4+$ and CD $8+$ T cells, respectively; $P=0.018$ for both comparisons). The proportions of naive and $\mathrm{T}_{\mathrm{CM}}$ were significantly greater in the CD4 + T-cell subset from PBMCs (medians $27 \%$ and $48 \%$, respectively) compared with cervix (medians $1.7 \%$ and $7.9 \%$, respectively; $P=0.018$ for both comparisons) while there was no statistically significant difference in the median proportion of $\mathrm{T}_{\mathrm{EMRA}}$ between the two compartments (1.6\% for PBMCs vs. $0.8 \%$ for cervix, $P=0.091)$. The proportions of naive and $\mathrm{T}_{\text {EMRA }}$ were significantly greater in the $\mathrm{CD} 8+\mathrm{T}$-cell subset from PBMCs (medians $30.3 \%$ and $11.1 \%$, respectively) compared with cervix (medians $0.6 \%$ and $2.7 \%$, respectively; $P=0.018$ for both comparisons) while there was no statistically significant difference in the median proportion of $\mathrm{T}_{\mathrm{CM}}$ between the two compartments $(10.8 \%$ vs. $3.3 \%, P=0.128)$.

The expression of CD69 and CD103, two proteins thought to enhance retention of $\mathrm{T}$ cells in tissue, ${ }^{16,17}$ was compared on total CD4 + and CD8 $+\mathrm{T}$ cells isolated from PBMCs and cervical samples. Representative data (Figure 2a) and summarized data (Figure 2b) show that CD69 was expressed on a higher proportion of $\mathrm{CD} 4+$ (medians $81.1 \%$ vs. $0.8 \%, P=0.008$ ) and $\mathrm{CD} 8+\mathrm{T}$ cells (medians $75.7 \%$ vs. $3.2 \%, P=0.008$ ) isolated from cervical biopsies vs. blood $(n=9)$. CD103 expression was also expressed on a higher proportion of CD4 + (medians $12.1 \%$ vs. $0.7 \%, P=0.008$ ) and $\mathrm{CD} 8+\mathrm{T}$ cells (medians $35.7 \%$ vs. $2.3 \%, P=0.008$ ) isolated from cervical biopsies vs. blood ( $n=9$; Figure $2 \mathbf{b}$ ). In addition, a higher proportion of $\mathrm{CD} 8+\mathrm{T}$ cells from the cervical biopsies expressed CD103 compared with CD4 $+\mathrm{T}$ cells (medians $35.7 \%$ vs. $12.1 \%, P=0.015$ ) while the expression of CD69 was similar between the T-cell subsets (medians 81.1 vs. 75.7, $P=0.213$ ). There was a similar trend toward high expression of CD69 and CD103 on total CD4 + and CD8 + from three cytobrush samples that were analyzed (Supplementary Figure 1A and data not shown).

Recently, Watanabe et al. ${ }^{18}$ described four functionally and phenotypically distinct populations of $\mathrm{T}$ cells isolated from the skin. Within both the CD4 + and CD8 + T-cell subsets, the expression of CD69 was used to distinguish the non-circulating resident population from the recirculating population. The CD69 + cells were considered resident memory $\left(\mathrm{T}_{\mathrm{RM}}\right)$ and were divided into $\mathrm{CD} 103+\mathrm{T}_{\mathrm{RM}}$ and $\mathrm{CD} 103-\mathrm{T}_{\mathrm{RM}}$, while 


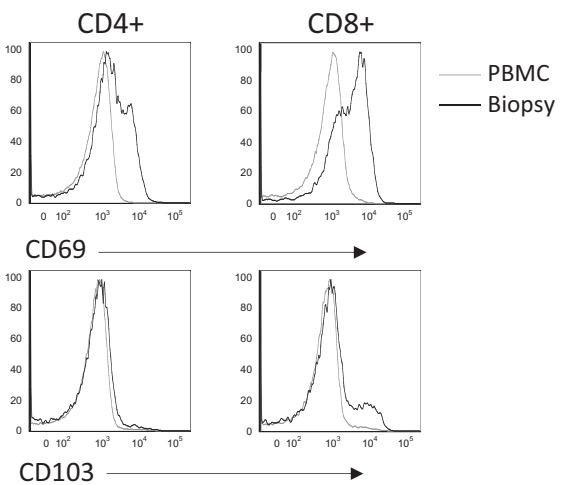

b

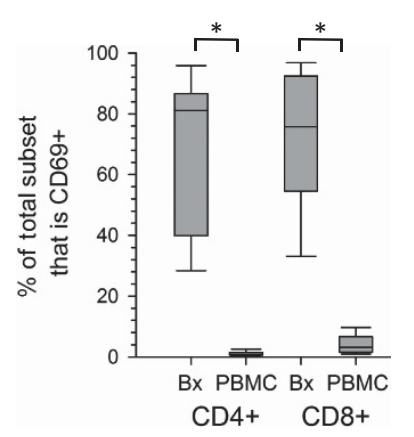

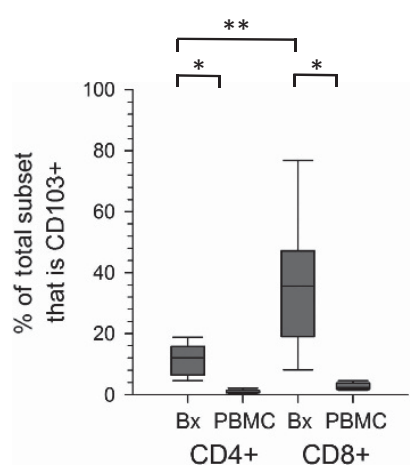

d
C

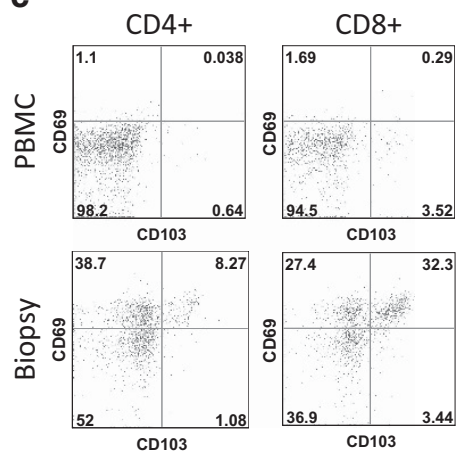

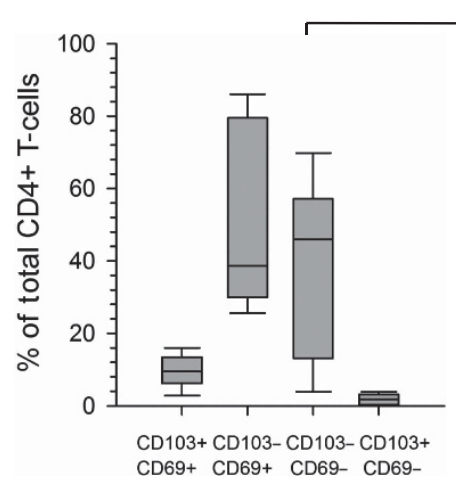

$P=0.015$

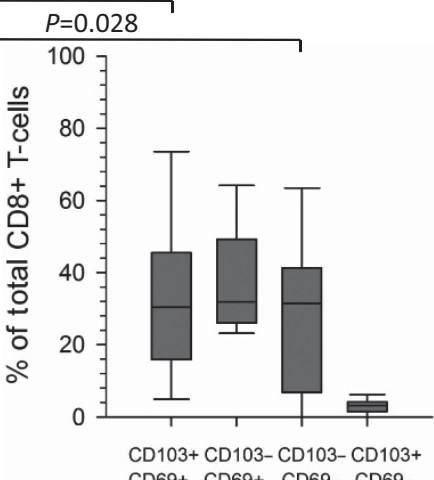

Figure 2 Expression of $\mathrm{T}_{\mathrm{RM}}$-associated markers on total T cells isolated from the cervix or PBMCs. (a) Representative histograms to measure the expression of CD69 and CD103 on CD4 + and CD8 + T cells. T cells isolated from PBMCs (gray line) or cervical biopsy (black line) from a representative participant were analyzed by flow cytometry. (b) Expression of CD69 and CD103 on T cells. The percentage contribution of CD69+ and CD103 + to the total CD4 + or CD8 + T-cell subset isolated from PBMC or cervical biopsy from HSV-2-infected participants $(n=9)$ is displayed. Each box displays the median, 25th and 75th percentiles and error bars display the 10th and 90th percentiles from HSV-2-infected participants $(n=9)$. $\left.{ }^{*} P=0.008 ;{ }^{* *} P=0.015\right)$. (c) Representative dotplots displaying the co-expression of CD103 and CD69 on PBMC or cervix-derived CD4 + and CD8 + T cells from a representative participant. (d) Co-expression of CD69 and CD103 on T cells derived from the cervix. The percentage contribution of each of four populations to the total CD4 + or CD8 + T-cell subset from cervix-derived T cells from HSV-2-infected participants $(n=9)$ is displayed. Each box displays the median, 25 th and 75th percentiles and error bars display the 10th and 90th percentiles.

potentially recirculating populations were CD69 - /CD103 and either $\mathrm{CCR} 7+/ \mathrm{L}$-selectin $+\left(\mathrm{T}_{\mathrm{CM}}\right)$ or $\mathrm{CCR} 7+/ \mathrm{L}$ selectin - (migratory memory or $\left.\mathrm{T}_{\mathrm{MM}}\right){ }^{18} \mathrm{U}$ sing this classification, we measured the co-expression of CD103 and CD69 on $\mathrm{CD} 4+$ and CD8 + T cells isolated from the cervix and blood. Representative dotplots (Figure 2c) show that while the majority of PBMC-derived CD4 + and $\mathrm{CD} 8+\mathrm{T}$ cells are CD69 - /CD103 - , cervix-derived CD4 + and CD8 + T cells are comprised of primarily three populations: $\mathrm{CD} 69+1$ $\mathrm{CD} 103+, \mathrm{CD} 69+/ \mathrm{CD} 103-$ and CD69-/CD103 - T cells. Summarizing data for total CD4 + or CD8 + T-cell subsets isolated from biopsies from nine HSV-2-infected women (Figure 2d), CD8 + T cells had similar proportions of $\mathrm{CD} 69+/ \mathrm{CD} 103+, \mathrm{CD} 69+/ \mathrm{CD} 103-$ and $\mathrm{CD} 69-/$ CD103 - (medians 30.4, 31.9, and 31.5\%, respectively), while $\mathrm{CD} 4+\mathrm{T}$ cells were comprised primarily of CD103 - cells that were either CD69 - (median 46.0\%) or CD69 + (median 38.7\%), with a lower proportion of CD69+ / $\mathrm{CD} 103+$ cells (median 9.5\%). Interestingly, CD69+/ $\mathrm{CD} 103+\mathrm{T}$ cells comprised a statistically significantly greater proportion of cervix-derived $\mathrm{CD} 8+\mathrm{T}$ cells compared with their CD $4+$ counterparts (medians $30.4 \%$ vs. $9.5 \%, P=0.015)$. The potentially recirculating population (CD69 - /CD103 - ) made up a median of $46.0 \%$ of CD4+ $\mathrm{T}$ cells and $31.5 \%$ of $\mathrm{CD} 8+\mathrm{T}$ cells (Figure $2 \mathrm{c} ; P=0.028$ ). The proportions of CD69+/CD103 - and CD69-/CD103+ were not statistically significantly different between the T-cell subsets $(P=0.139$ and $P=0.086$, respectively). Thus, the majority of cervix-derived CD $4+\mathrm{T}$ cells were CD103 $-\mathrm{T}_{\mathrm{RM}}$ in contrast to CD8 $+\mathrm{T}$ cells, which were comprised of similar proportions of CD103 + and CD103 $-\mathrm{T}_{\mathrm{RM}}$. A similar trend was observed in three cytobrush samples that were analyzed (Supplementary Figure 1A and data not shown).

\section{Ex vivo characterization of HSV-2-reactive CD4 $+\mathrm{T}$ cells derived from the cervix}

HSV-2-reactive CD4 + T cells were measured ex vivo from $\mathrm{T}$ cells obtained from cervical cytobrushes and biopsies. Figure 3 a displays the expression of IFN- $\gamma$ by CD $4+$ T cells isolated from a biopsy and stimulated ex vivo with mock or ultraviolet (UV)- 

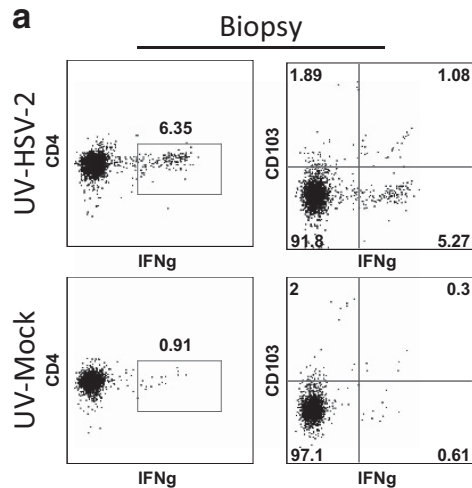

d
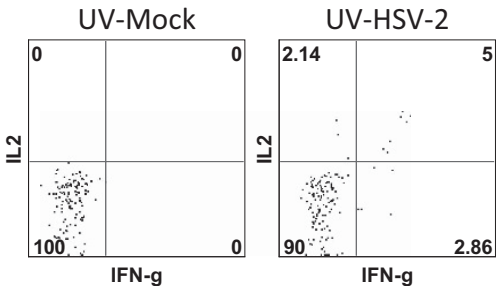
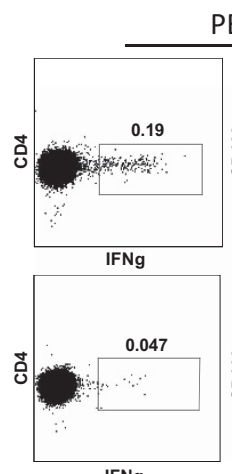

IFNg
PBMC
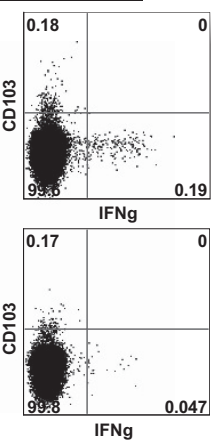

b

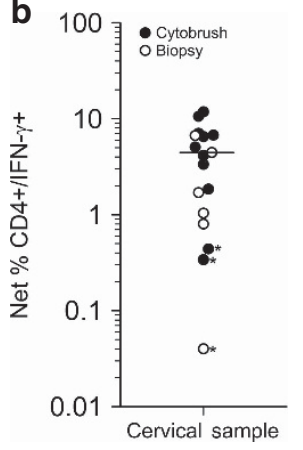

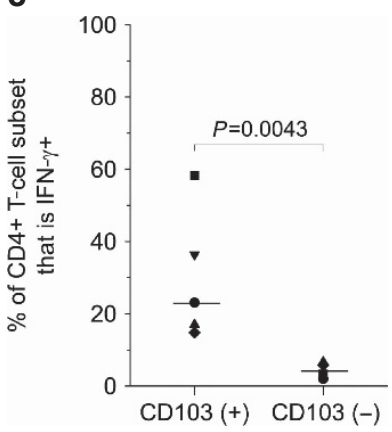
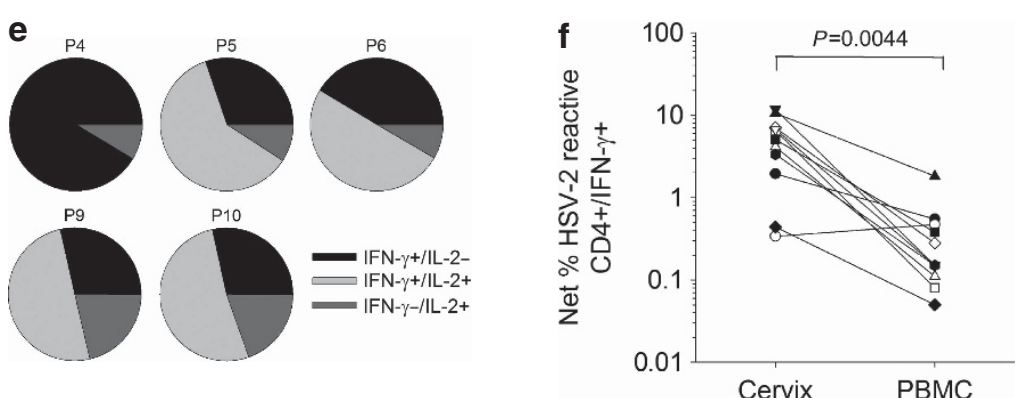

Figure 3 HSV-2-reactive CD4 + T cells are enriched in the CD103 + subset of cervical cells. The cells isolated from the cervix or blood were coincubated with UV-mock or UV-HSV-2 antigen and tested ex vivo for the expression of cytokines and CD103. (a) Representative dotplots comparing the reactivity of $\mathrm{CD} 103+$ and $\mathrm{CD} 103$ - cells for IFN- $\gamma$ expression in response to HSV-2 antigen. T cells from a cervical biopsy (left graphs) or PBMC (right graphs) from a representative participant were cultured with UV-mock (bottom graphs) or UV-HSV-2 (top graphs) and the resultant CD4 + T cells were analyzed by ICS and flow cytometry for the expression of IFN- $\gamma$ and CD103. (b) Net \% HSV-2-specific CD $4+$ T cells (CD4 $+/$ IFN- $\gamma+$ ) was measured in cytobrush and biopsy samples; *, proportion of CD $4+/$ IFN- $\gamma+$ cells stimulated with UV-HSV-2 not statistically significantly different than those stimulated with mock (Fisher's exact test $P>0.05$ ). Median of all cervical samples where $>100$ cells analyzed is depicted by the bar. (c) HSV-2-reactive CD4 + T cells are enriched in the CD103 $(+)$ subset. The percentage contribution of IFN- $\gamma+(\mathrm{HSV}-2$-reactive) cells to the total CD103( +$)$ and CD103 ( - ) CD4 + T-cell subsets from five participants is displayed. Bars represent the medians. (d) Representative dotplots displaying IFN- $\gamma$ and IL-2 expression on CD4 + T cells derived from a cervical cytobrush sample from a representative participant co-incubated with mock (bottom graph) or UVHSV-2 (top graph). (e) Co-expression of IFN- $\gamma$ and IL-2 by HSV-2-reactive CD4 + T cells derived from cervical cytobrushes. The percentage of single and dual cytokine expressing HSV-2-reactive CD4 + T cells relative to the total HSV-2-reactive CD4 + T-cell population is displayed. P, participant. (f) HSV2 -reactive CD4 + T cells are more abundant in the cervix compared with the blood. Net \% HSV-2-reactive CD $4+/ \mathrm{IFN}-\gamma+\mathrm{T}$ cells was calculated by ICS/ flow cytometry from $T$ cells derived from cervical cytobrushes (cervix) or PBMCs.

HSV-2. In total, cytobrushes and biopsies from $13 \mathrm{HSV}-2+$ women and $2 \mathrm{HSVneg}$ women were examined ex vivo for viral reactive $\mathrm{CD} 4+\mathrm{T}$-cell responses by intracellular cytokine staining (ICS) and flow cytometry. Next, we determined whether the proportion of CD $4+/$ IFN- $\gamma+$ cells co-incubated with HSV-2 was significantly greater from those co-incubated with mock antigen. ${ }^{19}$ Of the 18 cervical samples tested from HSV-2-infected women, CD4 + T cells from 14 of them (nine cytobrushes and five biopsies) were positive for HSV-2 reactivity (Figure $3 \mathbf{b}$ ). Data from 1 of the biopsy samples were excluded because fewer than 100 cells were gated and from 3 of the 18 cervical samples (two cytobrushes and one biopsy, * in Figure $3 \mathbf{b}$ ), the proportion of CD $4+/ \mathrm{IFN}-\gamma+$ cells from UV-HSV-2 co-incubated cultures was not statistically significantly greater than those co-incubated with UV-mock antigen (all analyses $P>0.05$ ). The median proportion of HSV2 -reactive $\mathrm{CD} 4+/ \mathrm{IFN}-\gamma+$ cells from all cervical samples with $>100$ cells gated was $4.45 \%$ (range $0.04-11.8 \%$ ). Of the two cervical cytobrush samples tested from the two HSVneg women, both had $>100$ cells gated but neither were positive for
HSV-2 reactive CD $4+\mathrm{T}$ cells (Supplementary Figure 1B). There was no statistically significant difference in the frequency of HSV-2-reactive CD4 + T-cell responses in women with and without HSV-1 coinfection: the median frequency of cervixderived HSV-2-reactive CD $4+$ T cells was 5.06\% in HSV-1 - I $2+$ women $(n=9)$ compared with $4.46 \%$ in HSV- $1+12+$ women $(n=6 ; P=0.317)$.

We next determined whether the HSV-2-reactive cervical cells expressed $\mathrm{T}_{\mathrm{RM}}$ phenotypic markers. As shown for biopsyderived cells from a representative subject (Figure 3a), approximately $17 \%$ of the $\mathrm{CD} 4+\mathrm{T}$ cells that co-expressed IFN- $\gamma$ in response to HSV-2 also expressed CD103. Of the five cervical samples tested, HSV-2-reactive $\mathrm{CD} 4+\mathrm{T}$ cells coexpressed CD103 at a median frequency of 17\% (range 13$75 \%$ ) in contrast to matched PBMC samples where CD103 expression on HSV-2-specific CD4 + T cells ranged from 0 to $2 \%$ (median $0 \% ; P=0.0043$; Figure 3a and data not shown). If we assess the proportion of CD103 + and CD103 - CD4 + cervical $\mathrm{T}$ cells that are IFN- $\gamma+$ (that is, $\mathrm{HSV}-2$ reactive), a median of $23.1 \%$ (range $14.8-58.3 \%$ ) of CD103 + cells are IFN- 
$\gamma+$ compared with $5.5 \%$ (range 2-6.7\%) of CD103 - cells $(P=0.0043$; Figure $3 c)$, suggesting that the HSV-2-specific $\mathrm{CD} 4+\mathrm{T}$ cells are enriched in the CD103 + subset populating the cervix.

In a subset of HSV-2-infected participants $(n=5)$, we assessed the co-expression of IFN- $\gamma$ and IL-2 from HSV-2reactive $\mathrm{CD} 4+\mathrm{T}$ cells; representative dotplots are displayed in Figure 3d. All five of the cytobrush samples tested contained $\mathrm{CD} 4+\mathrm{T}$ cells that expressed IL-2 in response to HSV-2 at frequencies ranging from 0.39 to $9.62 \%$ (median $4.17 \%$ ). Interestingly, the proportion of CD4 $+\mathrm{T}$ cells expressing IFN$\gamma$ in response to HSV-2 expression was significantly higher in these samples, with frequencies ranging from 4.14 to $10.58 \%$ $(P=0.043)$. With one exception (Participant 4$)$, at least $50 \%$ of total HSV-2-reactive CD4 + T-cell population expressed both IFN- $\gamma$ and IL-2 (Figure 3e).

\section{Enrichment of HSV-2-reactive CD4 + T cells in cervix compared with blood}

The frequency of HSV-2-reactive CD4 + T cells was measured in cervical samples and blood obtained during the same study visit. Representative data (Figure 3a) and summarized paired data (Figure 3f) are consistent with local enrichment in the FRT. Cells from both sites had statistically significantly greater expression of IFN- $\gamma$ from UV-HSV-2 stimulated CD $4+$ T cells (Figure 3a, top dotplots) compared with UV-mock stimulated cells (Figure 3a, bottom dotplots): the net \% HSV-2-reactive $\mathrm{CD} 4+\mathrm{T}$-cell response from $\mathrm{T}$ cells derived from this cervical biopsy vs. PBMC was $5.44 \%$ vs. $0.14 \%$, respectively. In total, we measured HSV-2-reactive CD4 + T-cell responses ex vivo in cytobrush samples from $11 \mathrm{HSV}-2+$ women (Figure 3f) and in biopsy samples from six HSV-2 + women (data not shown) along with their corresponding PBMC. In all but one cytobrush sample, the net \% HSV-2-reactive CD4 $+/ \mathrm{IFN}-\gamma+\mathrm{T}$-cell response was greater in the cervical samples compared with PBMCs. The median frequency of cytobrush-derived HSV-2reactive $\mathrm{CD} 4+\mathrm{T}$ cells was $5.06 \%$ compared with a median of $0.15 \%$ in PBMCs $(P=0.0044)$. There was a median 22 -fold enrichment (range 1- to 82-fold) of cytobrush-derived HSV-2reactive $\mathrm{CD} 4+\mathrm{T}$ cells compared with PBMC-derived cells. Similarly, there was a 25-fold (range 3-45) enrichment of cervical biopsy-derived HSV-2-reactive CD4 $+\mathrm{T}$ cells compared with PBMC-derived T cells (data not shown). Therefore, these data suggest that HSV-2-reactive $\mathrm{CD} 4+\mathrm{T}$ cells are enriched in the cervix compared with the circulation.

\section{Detection of HSV-2-reactive CD8 + T cells in cervical samples}

Previously, we demonstrated that HSV-2-reactive CD8 + T-cell activity in cervical T-cell lines was detected by ICS and flow cytometry by co-culturing the T-cell lines with autologous HSV-2-infected dendritic cells (DCs). ${ }^{14}$ We adapted this stimulation method to determine whether HSV-2-reactive $\mathrm{CD} 8+\mathrm{T}$ cells could be detected ex vivo in cervical biopsy samples. Figure 4a displays the expression of IFN- $\gamma$ by CD8 + $\mathrm{T}$ cells isolated from a cervical biopsy and incubated ex vivo with mock DCs or HSV-2 DCs. In total, six biopsies were
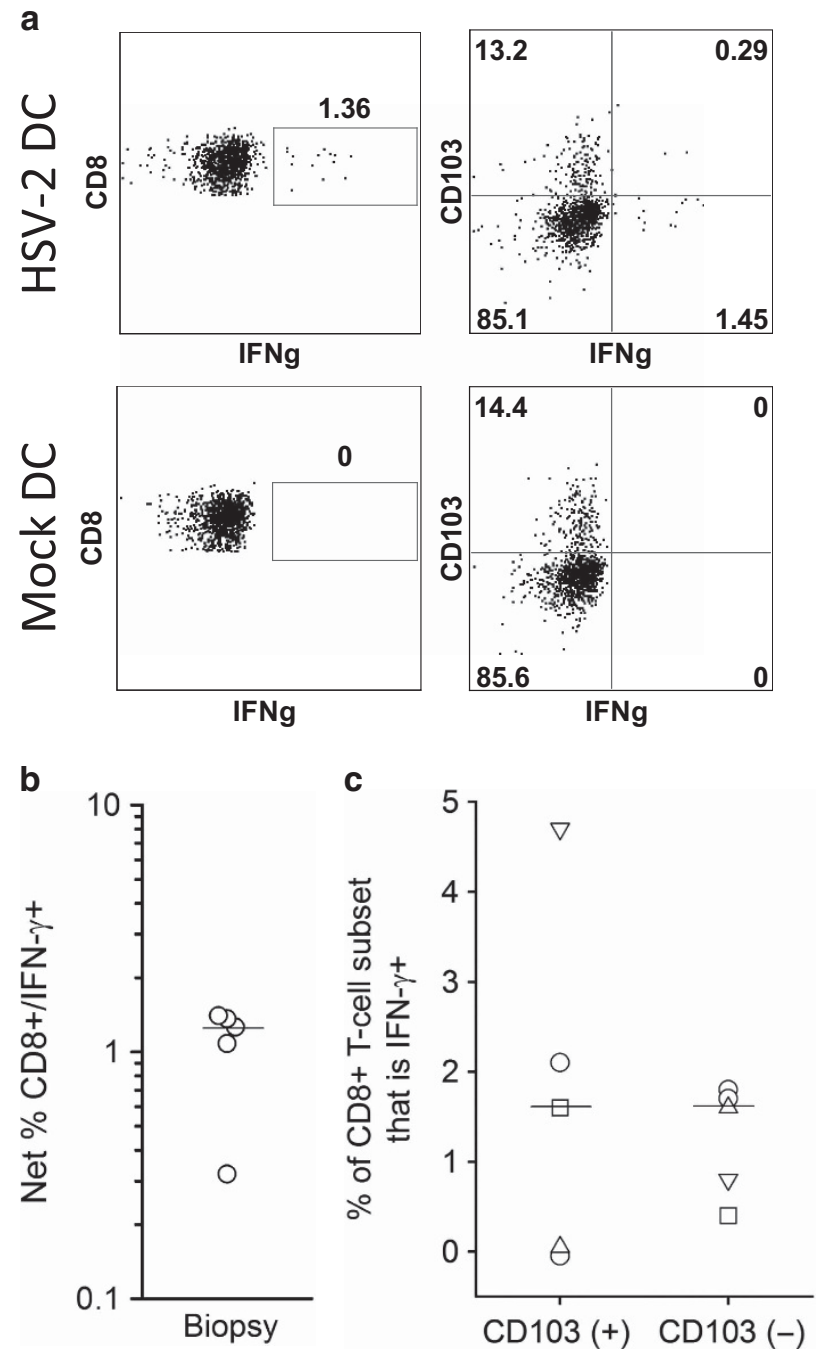

Figure 4 Detection of cervix-derived HSV-2-reactive CD8 + T cells using autologous HSV-2-infected DCs. The cells isolated from cervical biopsy samples were co-cultured with autologous mock-infected or HSV2-infected DCs and tested ex vivo for the expression of IFN- $\gamma$ and CD103. (a) Representative dotplots for the expression of IFN- $\gamma$ and CD103 by CD8 + T cells isolated from a cervical biopsy in response to mock DCs (bottom graphs) or HSV-2 DCs (top graphs). T cells were isolated from a cervical biopsy from a representative HSV-2-infected participant and cocultured with autologous mock DCs or HSV-2 DCs and the resultant CD8 + T cells were analyzed by ICS and flow cytometry for the expression of IFN- $\gamma$ and CD103. (b) Net \% HSV-2-reactive CD8 + T cells (CD8 + I IFN- $\gamma+$ ) was measured in biopsy samples from five HSV-2-infected subjects; the bar depicts the median of all cervical biopsy samples. (c) Expression of CD103 on HSV-2-reactive CD8 + T cells derived from cervical biopsies. The percentage contribution of IFN- $\gamma+(\mathrm{HSV}-2-$ reactive) cells to the total $\mathrm{CD} 103(+)$ and $\mathrm{CD} 103(-) \mathrm{CD} 8+\mathrm{T}$-cell subsets from five participants is displayed. Bars represent the medians.

examined ex vivo for viral reactive CD8 + T-cell responses by ICS and flow cytometry. As displayed in Figure $\mathbf{4 b}$, five of the cervical biopsy samples had statistically significantly greater proportions of CD $8+/$ IFN- $\gamma+$ cells co-incubated with HSV-2 DCs compared with mock DCs $(P<0.05$ by Fisher's exact test) while no measurable HSV-2-reactive CD8 $+\mathrm{T}$ cells were present in a biopsy from one subject. The median frequency of HSV-2-reactive CD8 + T cells from the cervical samples was $1.06 \%$ (range $0-1.68 \%$ ). 
We also measured the expression of CD103 on the CD $8+\mathrm{T}$ cells to determine whether the HSV-2-reactive CD8 + cervical $\mathrm{T}$ cells expressed $\mathrm{T}_{\mathrm{RM}}$ phenotypic markers. As shown for biopsy-derived cells from a representative subject (Figure 4a), $16.7 \%$ of the $\mathrm{CD} 8+\mathrm{T}$ cells that expressed IFN- $\gamma$ in response to HSV-2 DCs also co-expressed CD103. Of the five cervical samples with detectable HSV-2-reactive CD8 $+\mathrm{T}$ cells, the median proportion of HSV-2-reactive $\mathrm{CD} 8+\mathrm{T}$ cells that coexpressed CD103 was $16.7 \%$ (range $0-24.4 \%$ ). If we assess the proportion of CD103 + and CD103 - CD8 + cervical T cells that are IFN $-\gamma+$ (that is, $\mathrm{HSV}-2$ reactive), a median of $1.5 \%$ (range $0-2.1 \%$ ) of $\mathrm{CD} 103+$ cells are IFN- $\gamma+$ compared with $1.6 \%$ (range $0.4-1.8 \%)$ of CD103 - cells $(P=0.89$; Figure 4 c). These data suggest that HSV-2-reactive CD8 + T cells derived from the cervix are present in similar proportions of CD103+ and $\mathrm{CD} 103$ - populations.

\section{DISCUSSION}

Our ex vivo analysis of cervix-derived T cells from HSV-2infected women revealed that HSV-2-reactive $\mathrm{T}$ cells are present at this mucosal site and in sufficient quantities to analyze both phenotypic markers and functional characteristics. Total CD4 + and CD8 $+\mathrm{T}$ cells were primarily of the $\mathrm{T}_{\mathrm{EM}}$ phenotype (CCR7 - /CD45RA - ) ${ }^{15}$ and the expression of CD69 on the majority of both subsets distinguished them from PBMCs. The analysis of CD103 and CD69 on these cells revealed three distinct populations of both $\mathrm{CD} 4+$ and CD8 + T cells: CD69+/CD103 + cells were more abundant in the CD8 + T-cell subset compared with the CD4 + T-cell subset, whereas the $\mathrm{CD} 4+\mathrm{T}$-cell subset predominantly comprised the CD69 +/CD103 - cells. HSV-2-reactive CD4 $+\mathrm{T}$ cells expressed IFN- $\gamma$, IL-2, and CD103 and were significantly enriched in this mucosal compartment compared to the blood. Functional HSV-2-reactive CD8 + T cells were also detected in the cervix and similar proportions were $\mathrm{CD} 103+$ and CD103-.

In our prior studies, nonspecific polyclonal in vitro expansion of cervix-derived lymphocytes obtained from cytobrushes allowed us to assess the phenotype of total and HSV-2-reactive $\mathrm{CD} 3+\mathrm{T}$ cells as well as the specific viral antigens recognized by the HSV-reactive $\mathrm{T}$ cells. ${ }^{13,14}$ Total $\mathrm{CD} 3+\mathrm{T}$ cells were predominantly $\mathrm{CD} 4+$ and HSV-2-reactive $\mathrm{T}$ cells could be detected in cervical T-cell lines from the majority of HSV-2infected women. Interestingly, HSV-2-reactive CD4 $+\mathrm{T}$ cells showed greater antigenic diversity than their CD8 + counterparts. ${ }^{14}$ The data were also consistent with local enrichment, but the nonspecific polyclonal expansion before antigenspecific readouts left open the possibility that biased clonotype expansion could influence the relative abundance of HSV-2reactive cells. In our current study, we therefore directly measured both the phenotype of cervix-derived total $\mathrm{T}$ cells and the abundance of HSV-2 CD4 + reactive T cells in the cervix ex vivo. The majority of total CD3 $+\mathrm{T}$ cells derived from the cervix by cytobrush or biopsy were $\mathrm{CD} 4+$, although CD8 + $\mathrm{T}$ cells derived from biopsies made up a greater proportion of total $\mathrm{CD} 3+\mathrm{T}$ cells compared with those derived from cytobrushes (Figure 1). These data are similar to a comparison of the yield and profile of $\mathrm{T}$ cells from HIVnegative women obtained from cytobrushes and biopsy, which demonstrated that both methods resulted in the isolation of higher numbers of total CD4 $+\mathrm{T}$ cells compared with CD8 + $\mathrm{T}$ cells. ${ }^{20}$ We further showed that the vast majority of total $\mathrm{CD} 4+$ and $\mathrm{CD} 8+\mathrm{T}$ cells derived from the cervix were $\mathrm{T}_{\mathrm{EM}}$ (CCR7 - /CD45RA - ), in contrast to blood, which had a more balanced profile of naive, $\mathrm{T}_{\mathrm{EM}}, \mathrm{T}_{\mathrm{CM}}$, and $\mathrm{T}_{\mathrm{EMRA}}$ (Figure 1). These data are consistent with those obtained by the study of $\mathrm{T}$ cells obtained from mucosal tissue from human organ donors, which suggested that mucosal sites are predominantly populated with $\mathrm{CD} 4+$ and $\mathrm{CD} 8+\mathrm{T}_{\mathrm{EM}}$ and are stably maintained, ${ }^{21}$ although lymphocytes from the female genital tract were not analyzed in that study.

It is possible that collagenase digestion resulted in a loss of expression of cell surface markers such as CD4 and CCR7 in the biopsy samples compared with cytobrush and PBMC samples that were processed in the absence of collagenase; this would have resulted in underreporting of the frequencies of total $\mathrm{CD} 4+\mathrm{T}$ cells and over-reporting of $\mathrm{T}_{\mathrm{EM}}$ in the biopsy samples. Although tissue digestion with dispase had significant effects on many cell surface molecules, multiple rounds of low concentration of collagenase have been shown by others to have minimal effects on CD4. ${ }^{22,23}$ Regarding the CCR7 expression, we showed that total cytobrush-derived CD $4+$ and CD8 $+\mathrm{T}$ cells from three participants isolated in the absence of collagenase also contained higher proportions of $\mathrm{T}_{\mathrm{EM}}$ (Supplementary Figure 1A), similar to what was observed in the biopsy samples (Figure 1). Moreover, our data are consistent with a study of cervical $\mathrm{T}$ cells obtained by cytobrush demonstrating that the majority of CD4 + and CD8 + T cells analyzed ex vivo were $\mathrm{T}_{\mathrm{EM}} \cdot{ }^{24}$

The $\mathrm{T}$ cells derived from tissues are often distinguished from circulating T cells by the expression of CD69 and CD103, both of which are thought to enhance T-cell retention within peripheral tissues. Surface expression of CD69, an early leukocyte cell-activation marker, has been shown to interfere with sphingosine-1-phosphate receptor function leading to T-cell retention and local memory formation. ${ }^{16} \mathrm{CD} 103$, a constituent of $\alpha \mathrm{E} \beta 7$ integrin, participates in T-cell retention through interaction with E-cadherin expressed on epithelial cells. ${ }^{17}$ Studies of human organ donors revealed that the highest frequency of CD69 expression was on tissue-derived CD4 + and $\mathrm{CD} 8+\mathrm{T}_{\mathrm{RM}}$, and that $\mathrm{CD} 103$ was most highly expressed by gut-derived CD8 + T cells. ${ }^{21,25}$ Recently, the presence of four discrete populations of resident and recirculating memory $\mathrm{T}$ cells was described in human skin. ${ }^{18}$ Non-recirculating $\mathrm{T}_{\mathrm{RM}}$ were $\mathrm{CD} 69+$ and divided into $\mathrm{CD} 103+\mathrm{T}_{\mathrm{RM}}$ vs. CD103 $\mathrm{T}_{\mathrm{RM}}$, the former demonstrating superior effector function but less proliferative potential. ${ }^{18}$ Based on this terminology, the majority of the cervix-derived CD4 $+\mathrm{T}$ cells we analyzed were CD103 - $\mathrm{T}_{\mathrm{RM}}$ (high proliferative potential) while there was a significantly greater proportion of $\mathrm{CD} 103+\mathrm{T}_{\mathrm{RM}}$ (low proliferative potential) in the cervix-derived $\mathrm{CD} 8+\mathrm{T}$ subset (Figure 2d). If these CD8 $+\mathrm{CD} 103+\mathrm{T}_{\mathrm{RM}}$ indeed have less 
proliferative potential, it may explain at least in part why in our previous study of in vitro polyclonally expanded cervix-derived $\mathrm{T}$ cells were predominantly CD $4+.{ }^{14}$ Importantly, it emphasizes the need to analyze $\mathrm{T}$ cells ex vivo to more accurately quantify the proportions of resident and recirculating $\mathrm{T}$ cells within the cervix to achieve an unbiased assessment of the phenotypic makeup of these mucosal $\mathrm{T}$ cells.

Approximately $17 \%$ of the HSV-2-reactive CD4+ and $\mathrm{CD} 8+\mathrm{T}$ cells derived from the cervix expressed CD103. Although a higher proportion of total cervix-derived CD8 $+\mathrm{T}$ cells expressed CD103 compared with total cervix-derived $\mathrm{CD} 4+\mathrm{T}$ cells, interestingly, HSV-2 CD $4+\mathrm{T}$ cells were enriched in the CD103 + population compared with the HSV2-reactive $\mathrm{CD} 8+\mathrm{T}$ cells, which were equally distributed among the $\mathrm{CD} 103+$ and $\mathrm{CD} 103$ - populations. Although we cannot rule out the possibility that $\mathrm{T}$-cell stimulation results in the downregulation of CD103 on the HSV-2-reactive T cells, further analysis will be required to determine the relative contributions of $\mathrm{CD} 103+$ and $\mathrm{CD} 103$ - populations and whether the cervix-derived HSV-2-reactive T cells are comprising non-recirculating CD69+/CD103 $-\mathrm{T}_{\mathrm{RM}}$ as described by Watanabe et al. ${ }^{18}$ Recently, we have optimized the stimulation of blood-derived HSV-2-reactive CD8 $+\mathrm{T}$ cells using cross-presentation ${ }^{26}$ and are using this strategy to more fully assess the quantity and phenotype of HSV-2-reactive $\mathrm{CD} 8+\mathrm{T}$ cells populating the cervix. Our ability to analyze cervix-derived HSV-2-reactive CD8 + T cells ex vivo will allow us to more accurately characterize the functional capacity of $\mathrm{T}$ cells residing in this important site of HSV-2 infection and reactivation. This is especially important for qualitative analysis of cells with apparently decreased in vitro proliferative potential such as CD8alpha $(+) /$ beta $(-) \mathrm{T}$ cells, that reside in the skin at the dermal-epidermal junction and appear to have an important role in immunosurveillance. ${ }^{27}$

The role of $\mathrm{CD} 4+\mathrm{T}$ cells within tissues has been largely understudied compared with their CD8 + T-cell counterparts. Evidence suggests that $\mathrm{CD} 4+\mathrm{T}_{\mathrm{RM}}$ predominate in tissue and are integral for in situ protective immunity in mucosal sites including the lung and the vagina. ${ }^{28-31}$ Recently, elegant parabiosis experiments demonstrated that uterine $\mathrm{CD} 4+\mathrm{T}_{\mathrm{RM}}$ generated by mucosal immunization with a candidate Chlamydia vaccine were required for optimal protection from lethal challenge. ${ }^{32}$ A protective role of IFN- $\gamma$ has been demonstrated in several models of mucosal viral infection. CD4 + T-cellderived IFN- $\gamma$ was necessary for generating lung-resident $\mathrm{CD} 103+\mathrm{CD} 8+\mathrm{T}_{\mathrm{RM}}$ after influenza virus infection in mice; in the absence of this CD4 $+\mathrm{T}$-cell help, CD8 $+\mathrm{T}$ cells were impaired in their ability to mediate protection against viral challenge. ${ }^{31}$ In the murine vaginal model of HSV, the expression of IFN- $\gamma$ from $\mathrm{CD} 4+\mathrm{T}$ cells was critical for CD8 + T-cell mobilization and protection from lethal HSV infection. ${ }^{30,33}$ In the current study, the proportion of HSV-2reactive $\mathrm{CD} 4+\mathrm{T}$ cells expressing IFN- $\gamma$ was higher than those producing IL-2 and both were well above the level of reactivity of $0.30 \%$ noted in our cross-sectional study of PBMCs from 67 HSV-2-infected persons. ${ }^{34}$ The ex vivo analysis of HSV-2- reactive $\mathrm{T}$ cells confirmed our initial observations ${ }^{13,14}$ that HSV-2-reactive T cells are significantly enriched in the cervix compared with blood (Figure 3f). Further study of the factors produced by cervix-derived HSV-2-reactive CD $4+\mathrm{T}$ cells will be required to assess the possible protective mechanism(s) of these cells.

To our knowledge, this is the first demonstration of HSV-2reactive $\mathrm{T}$-cell functional responses measured ex vivo from a mucosal surface. It is possible that the UV-HSV-2 or HSV-DC stimulation of the cervix-derived $\mathrm{T}$ cells triggered non-antigen specific T-cell responses. However, we did not detect HSV-2reactive $\mathrm{CD} 4+\mathrm{T}$ cells ex vivo in cervical $\mathrm{T}$ cells obtained from two HSVneg women. Moreover, nonspecific polyclonal expansion of cervical cytobrush-derived $\mathrm{T}$ cells from five of the HSV-2-infected participants contained HLA-restricted $\mathrm{CD} 4+$ and $\mathrm{CD} 8+\mathrm{T}$ cells that were reactive to HSV-2 peptides, ${ }^{14}$ suggesting the presence of bona fide HSV-2-reactive $\mathrm{T}$ cells in the initial cervical cytobrush sample.

Most recognized HSV-2 recurrences are on the external genitalia in men and women. However, the cervix also appears to be a physiologically significant site of infection. HSV infection of the cervix, including ulcers, has been demonstrated by colposcopy examination, most frequently in the context of primary infection, ${ }^{35}$ whereas the prevalence of cervical involvement during typical recurrent genital herpes in women has not been well characterized. The frequent detection and enrichment of HSV-specific T cells in the cervix suggests either intermittent exposure to antigen or long-term persistence of cells after primary infection. Cervical shedding of HSV-2 tends to occur at lower rates than from other areas of the lower genital tract. ${ }^{36}$ However, HSV infection of the uterine cervix as measured by cell culture was detected in $5.2 \%$ of women in a large cross-sectional study, ${ }^{37}$ and we showed that HSV-2 DNA was present in $5-7 \%$ of CVL samples. ${ }^{14,38}$ It is also possible that the cervical cells we detected in this study are long-persisting $\mathrm{T}_{\mathrm{RM}}$ that are not maintained by local re-exposure to antigen. Rigorous examination of the role of local antigen awaits the licensing of highly effective anti-HSV drugs: the currently licensed compounds have significant breakthroughs of viral shedding when measured by sensitive methods ${ }^{2}$ such that we are not currently able to remove antigen from the system.

Our findings, placed into the current context of HSV and T-cell immunology, suggest further studies to better define FRT $\mathrm{T}_{\mathrm{RM}}$. We have published HSV-2-specific HLA class II tetramers that can detect peptide-specific CD4 T-cells ex vivo. ${ }^{39}$ Singlecell transcriptomics and highly dimensional protein methods (CyTOF) could be used to compare blood- and FRT-derived tetramer $(+) \mathrm{T}$-cells to discover further $\mathrm{T}_{\mathrm{RM}}$ markers. Therapeutic vaccines that have shown activity against FRT HSV-2 shedding and lesions have reached phase II in clinical trials ${ }^{5}$ but their effects, if any, on antigen-specific or total $\mathrm{T}_{\mathrm{RM}}$ are unknown. Antiviral compounds applied directly to the FRT can reduce the risk of HSV-2 acquisition, ${ }^{40}$ have complex immune signatures, ${ }^{41}$ and remain under consideration for HIV-1 prevention. Their effect on $\mathrm{T}_{\mathrm{RM}}$ should be investigated. More fundamentally, TCR CDR3 signatures can now be derived for 
HSV-2-specific T-cells in the circulation and in skin biopsies using next-generation sequencing methods to demonstrate overlap in cutaneous $\mathrm{T}_{\mathrm{RM}} ;{ }^{27}$ these have not yet been applied to cervical samples.

In summary, this study assessed functional HSV-2-reactive T-cell responses of lymphocytes isolated from the human FRT and showed that they are enriched in this mucosal compartment compared with the circulation. The expression of differentiation and tissue-specific markers on $\mathrm{T}$ cells derived from the human FRT revealed distinct populations of $\mathrm{CD} 4+$ and $\mathrm{CD} 8+\mathrm{T}$ cells that may relate to their retention and control at the sites of HSV-2 exposure and infection. The further study of $\mathrm{T}$ cells in the FRT ex vivo should provide mechanistic data that may lead to correlates of immune protection and novel strategies to prevent HSV-2 infection.

\section{METHODS}

Study population. Healthy HSV-2-seropositive and HSV-1- and HSV-2-seronegative women at least 18 years old were enrolled into IRB-approved protocols at the University of Washington Virology Research Clinic (VRC), Seattle, WA, USA. Women were excluded from the study if they were HIV-seropositive, pregnant, or had undergone a hysterectomy. All the participants provided written informed consent. HSV western blot to detect antibodies to HSV-1 and HSV-2 was performed as previously described. ${ }^{42,43}$

Cervical mucosal sample collection and transport. The samples were collected between menstrual cycles to prevent menstrual blood in cervical samples. The CVL fluid was obtained to measure HSV DNA by washing the cervical os and posterior vaginal wall with $10 \mathrm{ml}$ of phosphate-buffered saline ( $\mathrm{pH} 7.0$ ) as previously described. ${ }^{44}$ Cervical $\mathrm{T}$ cells were collected by cytobrush or biopsy during speculum examination. The Cytobrush Plus Cell Collector (Medscand, CA, USA) was inserted into the cervical os, rotated through $360^{\circ}$ once, and immediately placed in $5 \mathrm{ml}$ of cold transport medium RPMI-CVX (RPMI 1640 medium supplemented with $5 \mathrm{mM}$ L-glutamine, 50 $\mathrm{U} \mathrm{ml}^{-1}$ penicillin, $50 \mu \mathrm{g} \mathrm{ml}^{-1}$ streptomycin, and $10 \%$ human serum, $2.5 \mu \mathrm{g} \mathrm{ml}^{-1}$ amphotericin $\mathrm{B}$, and $5 \mu \mathrm{g} \mathrm{ml}^{-1}$ ciprofloxacin). One biopsy was obtained using a Baby Tischler Biopsy Forceps (Wallach Surgical, Trumbull, CT, USA) with a $4.2 \times 2.3 \mathrm{~mm}$ bite size. The biopsy was placed in $5 \mathrm{ml}$ of RPMI-CVX. No local injection anesthetic was used before biopsy collection. The order of sample collection was CVL, cytobrush, then biopsy. The cervical samples with visible red blood cell contamination were discarded. All the samples were transported to the laboratory on wet ice and processed within $4 \mathrm{~h}$ of collection.

CVL processing. The samples were centrifuged at $1,000 \times g$ for $20 \mathrm{~min}$ at $4{ }^{\circ} \mathrm{C}$, aliquoted, and stored at $-80{ }^{\circ} \mathrm{C}$ as previously described. ${ }^{44}$

Cytobrush processing. Under sterile conditions, the cervical cells were isolated as previously described. ${ }^{14}$ Briefly, the cells were dislodged from the sides of the tube by vortexing, the transport medium flushed through the cytobrush bristles, and the cell suspension passed through a $40 \mu \mathrm{m}$ filter into a clean $50-\mathrm{ml}$ centrifuge tube. The cells were pelleted at $250 \times g$ for $10 \mathrm{~min}$, resuspended in RPMI-CVX and counted.

Biopsy processing. The cells were isolated from biopsies by collagenase digestion as described in detail in ref. ${ }^{20}$. Briefly, the biopsies were cut into smaller pieces with sterile razor blades, placed in warm collagenase digestion media $\left(1 \mathrm{mg} \mathrm{ml}^{-1}\right.$ collagenase type II (SigmaAldrich C6885, St. Louis, MO, USA) in a 1:1 mixture of phosphatebuffered saline and R15 (RPMI 1640 medium supplemented with $5 \mathrm{~mm}$ L-glutamine, $50 \mathrm{U} \mathrm{ml}^{-1}$ penicillin, $50 \mu \mathrm{g} \mathrm{ml}^{-1}$ streptomycin, and $15 \%$ heat inactivated fetal bovine serum (Gemini Bio-Products, West Sacramento, CA, USA)) with 1 unit $\mathrm{ml}^{-1}$ DeoxyRibonuclease I
(DNase) (Sigma) and shaken at 200 r.p.m. in a $37^{\circ} \mathrm{C}$ incubator for $30 \mathrm{~min}$. The samples were then expelled through a 16-gauge needle 10 times and passed through a $70 \mu \mathrm{m}$ cell strainer into fresh R15. The tissue collected on the strainer was placed in fresh collagenase digestion media with DNase and the cycle repeated four times. During subsequent rounds of digestion, the cell suspension was centrifuged and cell pellets resuspended in R15 and kept on ice. Pooled cells from serial digestions were used for analysis.

PBMCs, DCs, and viruses. The PBMCs were isolated by FicollHypaque and analyzed ex vivo or cryopreserved within $8 \mathrm{~h}$ of venipuncture as previously described. ${ }^{45}$ The DCs were generated from PBMCs using granulocyte-macrophage colony-stimulating factor and interleukin- 4 as previously described. ${ }^{46} \mathrm{HSV}-2$ strain 333 was used at a multiplicity of infection of 10 or was UV-inactivated to use as viral antigen where indicated.

Surface staining, ICS, and flow cytometry. Total cells isolated from cervical samples or PBMCs were surface stained to assess the expression of T-cell subsets (CD4 and CD8), markers of T-cell differentiation (CCR7 and CD45RA), and markers of tissue residency (CD103 and CD69). The cells were suspended in phosphate-buffered saline and stained with the LIVE/DEAD Fixable Aqua Dead Cell Stain kit (Life Technologies, Grand Island, NY, USA). To analyze T-cell differentiation, the cells were washed in FACS wash ((phosphatebuffered saline containing $1 \%$ bovine serum albumin (Sigma)), and stained with the Human Naive/Memory T Cell Panel (CD3 APC-Cy7, CD4-PerCP-Cy5.5, CCR7-APC, and CD45RA-FITC; BD Biosciences, San Jose, CA) per manufacturer's recommendation; gating focused attention on live $\mathrm{CD} 3+$ cells in the lymphocyte forward/side scatter region that were $\mathrm{CD} 4+$ or $\mathrm{CD} 4$-negative, the latter of which was considered CD8 + for quantification. To analyze markers of tissue residency, the cells were washed in FACS wash and stained with CD3-APC-Cy7, CD4-PerCP-Cy5.5, CD69-APC, and CD103-PE (all from $\mathrm{BD}$ ).

ICS and flow cytometry was used to assess the expression of CD103 and cytokine production (IFN- $\gamma$ and IL-2) from virus-reactive T cells derived from the cervix and PBMCs. To measure CD4 + T-cell responses to HSV-2 ex vivo, T cells isolated from cervical samples or PBMCs were co-incubated with UV-mock antigen (negative control) or UV-HSV-2 for $6 \mathrm{~h}$. To measure CD8 + T-cell responses to HSV-2 ex vivo, T cells isolated from cervical samples were co-incubated with mock DCs (negative control) or DCs previously infected for $18 \mathrm{~h}$ with HSV-2 (HSV-2 DCs) (50,000 per well). ICS and flow cytometry was performed using a six-color ICS panel in a 96-well plate format modified from ref. 19 as previously described ${ }^{47}$ with modifications. During the $6 \mathrm{~h}$ incubation at $37^{\circ} \mathrm{C}$, brefeldin A $\left(10 \mu \mathrm{g} \mathrm{ml}{ }^{-1}\right.$, Sigma, St. Louis, MO, USA) and co-stimulatory antibodies specific for CD28 and CD49d (each at $1 \mu \mathrm{g} \mathrm{ml}^{-1}, \mathrm{BD}$ ) were included. The cells were stained with the LIVE/DEAD Fixable Violet Dead Cell Stain Kit (Life Technologies) and antibodies CD3-ECD (Beckman Coulter, Marseille, France), CD4-FITC, CD8-PerCp-Cy5.5, IFN- $\gamma$-APC, and IL-2-PE or CD103-PE (all from BD). Gating focused attention on live CD3 + cells in the lymphocyte forward/side scatter region that were CD4 or CD8 single-positive. The samples were collected from 96 -well plates using High Throughput Sample (HTS, BD) device for analysis by the LSRII and all FACS analyses were performed using FlowJo software (Treestar, Inc., Ashland, OR, USA).

Measurement of HSV DNA in cervical secretions. The CVL fluid was evaluated for HSV DNA by quantitative, real-time, fluorescence-based PCR as described. ${ }^{48}$

Statistical analysis. For a cervical sample to be considered positive for HSV-2-reactive T cells, the percentage of cytokine-positive $\mathrm{T}$ cells cultured with viral antigen needed to be statistically significantly greater than the percentage of cytokine-positive $\mathrm{T}$ cells cultured with control antigen (mock). Fisher's exact tests were used to compare the 
rate of cytokine production between the stimulated (HSV-2) and negative control (mock) cells for each cytokine subset (IFN- $\gamma$, IL-2) as previously described; ${ }^{19}$ statistical significance was defined as $P<0.05$. Results were considered invalid if fewer than 100 events were analyzed. The Wilcoxon signed-rank test was used to determine the differences between samples that were paired and the Wilcoxon rank-sum test was used to determine the difference when samples were not paired; statistical significance was defined as $P<0.05$ with two-tailed $\alpha$. We compared the proportion of total CD3 $+\mathrm{T}$ cells that were $\mathrm{CD} 4+$ and CD8 + cells between cervical cytobrushes and biopsies and the proportion of total CD4 + and CD8 $+\mathrm{T}$ cells that were CD69+, $\mathrm{CD} 103+$, naive, $\mathrm{T}_{\mathrm{CM}}, \mathrm{T}_{\mathrm{EM}}$, and $\mathrm{T}_{\mathrm{EMRA}}$ between PBMC- and biopsyderived T cells. We also compared the proportion of HSV-2-reactive T cells from each compartment that were CD103 + and the proportion of $\mathrm{CD} 103+$ and $\mathrm{CD} 103$ - cells that were IFN- $\gamma+$. Finally, we compared the frequencies of HSV-2-reactive CD4 $+\mathrm{T}$ cells between PBMC-, cervical cytobrush-, and cervical biopsy-derived T cells.

SUPPLEMENTARY MATERIAL is linked to the online version of the paper at http://www.nature.com/mi

\section{ACKNOWLEDGMENTS}

This study was supported by the National Institute of Allergy and Infectious Diseases, National Institutes of Health, grants R21 Al-083418 and R01 Al091701 to C.M.P., P01 Al-030731 to A.W., C.J., J.Z., A.S.M., and D.M.K., R01 Al-111780 to J.Z., R01 Al-42528 to L.C. and J.Z., and R01 Al-094019 to D.M.K. We thank Dr Florian Hladik for sharing his expertise regarding the isolation of T cells from cervical biopsies; Dawn Mueller and Sean Hughes for technical assistance; Dana Varon and Steve Kuntz for clinical expertise in obtaining cervical biopsies; Dr Meei Li Huang and Anna Rashevsky for performing the HSV PCR; Emma Robinson, Adi Braun, and Julie Thach for participant scheduling; Stacy Selke for clinical data management; and Cindy Hirano, Kirsten Hauge, and Lynn Wang for assistance with Institutional Review Board protocols.

\section{AUTHOR CONTRIBUTIONS}

C.M.P. conceived the study and designed the experiments, C.M.P., L.Z., L.D., and L.J. performed the experiments, C.E.S. obtained the clinical samples, A.S.M. provided statistical guidance and analysis, C.J. and A.W. supervised the clinical staff and provided input related to the clinical study design, J.Z., L.C., and D.M.K. provided scientific input related to study design, C.M.P. and D.M.K. wrote the manuscript, and all the authors edited the manuscript and contributed to the discussion.

\section{DISCLOSURE}

C.M.P. and L.C. are co-inventors on several patents involving potential HSV vaccine candidates. D.M.K. is listed as a co-inventor on patents describing T-cell responses to HSV-2 and is a consultant to Agenus. L.C. is on the scientific advisory board for and holds stock ( $<1 \%$ of company) in Immune Design Corp. A.W. received grants from Agenus, Genentech, Genocea, Gilead, and Vical, received royalties from UptoDate, and has been a consultant for Aicuris, Eisai, and Amgen. C.J. has received research support from Aicuris $\mathrm{GmbH}$.

c) 2017 Society for Mucosal Immunology

\section{REFERENCES}

1. Freeman, E.E., Weiss, H.A., Glynn, J.R., Cross, P.L., Whitworth, J.A. \& Hayes, R.J. Herpes simplex virus 2 infection increases HIV acquisition in men and women: systematic review and meta-analysis of longitudinal studies. AIDS 20, 73-83 (2006).

2. Johnston, C. et al. Standard-dose and high-dose daily antiviral therapy for short episodes of genital HSV-2 reactivation: three randomised, openlabel, cross-over trials. Lancet 379, 641-647 (2012).

3. Johnston, C., Koelle, D.M. \& Wald, A. Current status and prospects for development of an HSV vaccine. Vaccine 32, 1553-1560 (2014).
4. Hofstetter, A.M., Rosenthal, S.L. \& Stanberry, L.R. Current thinking on genital herpes. Curr. Opin. Infect. Dis 27, 75-83 (2014).

5. Wald, A. et al. Therapeutic HSV-2 Vaccine (GENO03) Results in Durable Reduction in Genital Lesions at 1 Year. Open Forum Infectious Diseases 1, S1-S65 (2014).

6. Schenkel, J.M. \& Masopust, D. Tissue-resident memory T cells. Immunity 41, 886-897 (2014).

7. lijima, N. \& Iwasaki, A. Tissue instruction for migration and retention of TRM cells. Trends Immunol. 36, 556-564 (2015).

8. Carbone, F.R. Tissue-resident memory $T$ cells and fixed immune surveillance in nonlymphoid organs. J. Immunol. 195, 17-22 (2015).

9. Parr, M.B. \& Parr, E.L. Intravaginal administration of herpes simplex virus type 2 to mice leads to infection of several neural and extraneural sites. J. Neurovirol. 9, 594-602 (2003).

10. Khoury-Hanold, W. et al. Viral spread to enteric neurons links genital HSV-1 infection to toxic megacolon and lethality. Cell Host Microbe 19, 788-799 (2016).

11. Tronstein, E. et al. Genital shedding of herpes simplex virus among symptomatic and asymptomatic persons with HSV-2 infection. JAMA 305, 1441-1449 (2011).

12. Ouwendijk, W.J., Laing, K.J., Verjans, G.M. \& Koelle, D.M. T-cell immunity to human alphaherpesviruses. Curr. Opin. Virol 3, 452-460 (2013).

13. Koelle, D.M., Schomogyi, M. \& Corey, L. Antigen-specific Tcells localize to the uterine cervix in women with genital herpes simplex virus type 2 infection. J. Infect. Dis. 182, 662-670 (2000).

14. Posavad, C.M. et al. Persistence of mucosal T-cell responses to herpes simplex virus type 2 in the female genital tract. Mucosal Immunol 8, 115-126 (2015).

15. Geginat, J., Lanzavecchia, A. \& Sallusto, F. Proliferation and differentiation potential of human CD8 + memory T-cell subsets in response to antigen or homeostatic cytokines. Blood 101, 4260-4266 (2003).

16. Mackay, L.K. et al. Cutting edge: CD69 interference with sphingosine-1phosphate receptor function regulates peripheral $T$ cell retention. J. Immunol. 194, 2059-2063 (2015).

17. Hadley, G.A. \& Higgins, J.M. Integrin alphaEbeta7: molecular features and functional significance in the immune system. Adv. Exp. Med. Biol. 819, 97-110 (2014).

18. Watanabe, R. et al. Human skin is protected by four functionally and phenotypically discrete populations of resident and recirculating memory $T$ cells. Sci. Transl. Med. 7, 279 ra39 (2015).

19. Horton, $\mathrm{H}$. et al. Optimization and validation of an 8-color intracellular cytokine staining (ICS) assay to quantify antigen-specific Tcells induced by vaccination. J. Immunol. Methods 323, 39-54 (2007).

20. McKinnon, L.R. et al. Optimizing viable leukocyte sampling from the female genital tract for clinical trials: an international multi-site study. PLoS One $\mathbf{9}$, e85675 (2014).

21. Thome, J.J. et al. Spatial map of human T cell compartmentalization and maintenance over decades of life. Cell 159, 814-828 (2014).

22. Autengruber, A., Gereke, M., Hansen, G., Hennig, C. \& Bruder, D. Impact of enzymatic tissue disintegration on the level of surface molecule expression and immune cell function. Eur. J. Microbiol. Immunol. 2, 112-120 (2012).

23. He, X., de Oliveira, V.L., Keijsers, R., Joosten, I. \& Koenen, H.J. Lymphocyte isolation from human skin for phenotypic analysis and ex vivo cell culture. J. Vis. Exp. 110, e52564 (2016).

24. Nkwanyana, N.N. et al. Impact of human immunodeficiency virus 1 infection and inflammation on the composition and yield of cervical mononuclear cells in the female genital tract. Immunology 128, e746-e757 (2009).

25. Sathaliyawala, T. et al. Distribution and compartmentalization of human circulating and tissue-resident memory $\mathrm{T}$ cell subsets. Immunity $\mathbf{3 8}$, 187-197 (2013).

26. Jing, L. et al. Extensive CD4 and CD8 T cell cross-reactivity between alphaherpesviruses. J. Immunol. 196, 2205-2218 (2016).

27. Zhu, J. et al. Immune surveillance by CD8alphaalpha + skin-resident $T$ cells in human herpes virus infection. Nature 497, 494-497 (2013).

28. Turner, D.L. \& Farber, D.L. Mucosal resident memory CD4 T cells in protection and immunopathology. Front. Immunol 5, 331 (2014).

29. Teijaro, J.R., Turner, D., Pham, Q., Wherry, E.J., Lefrancois, L. \& Farber, D.L. Cutting edge: tissue-retentive lung memory CD4 T cells mediate 
optimal protection to respiratory virus infection. J. Immunol. 187, 5510-5514 (2011).

30. Nakanishi, Y., Lu, B., Gerard, C. \& Iwasaki, A. CD8(+) T lymphocyte mobilization to virus-infected tissue requires $\mathrm{CD} 4(+)$ T-cell help. Nature 462, 510-513 (2009).

31. Laidlaw, B.J. et al. CD4 + T cell help guides formation of CD103 + lungresident memory CD8 + T cells during influenza viral infection. Immunity 41, 633-645 (2014).

32. Stary, G. et al. VACCINES. A mucosal vaccine against Chlamydia trachomatis generates two waves of protective memory T cells. Science 348, aaa8205 (2015).

33. lijima, N. \& Iwasaki, A. T cell memory. A local macrophage chemokine network sustains protective tissue-resident memory CD4 Tcells. Science 346, 93-98 (2014).

34. Moss, N.J. et al. Peripheral blood CD4 T-cell and plasmacytoid dendritic cell $(\mathrm{pDC})$ reactivity to herpes simplex virus 2 and $\mathrm{pDC}$ number do not correlate with the clinical or virologic severity of recurrent genital herpes. J. Virol. 86, 9952-9963 (2012).

35. Paavonen, J. et al. Colposcopic manifestations of cervical and vaginal infections. Obst. Gynec. Survey 43, 373-381 (1988).

36. Tanton, C. et al. Patterns of herpes simplex virus shedding over 1 month and the impact of acyclovir and HIV in HSV-2-seropositive women in Tanzania. Sex. Transm. Infect. 87, 406-411 (2011).

37. Eggert-Kruse, W., Mildenberger-Sandbrink, B., Schnitzler, P., Rohr, G., Strowitzki, T. \& Petzoldt, D. Herpes simplex virus infection of the uterine cervix-relationship with a cervical factor?. Fertility and Sterility 73, 248-257 (2000).

38. Aumakhan, B. et al. Genital herpes evaluation by quantitative TaqMan PCR: correlating single detection and quantity of HSV-2 DNA in cervicovaginal lavage fluids with cross-sectional and longitudinal clinical data. Virol. J. 7, 328 (2010).

39. Johnston, C. et al. Virologic and immunologic evidence of multifocal genital herpes simplex virus 2 infection. J. Virol. 88, 49214931 (2014)

40. Abdool Karim, S.S. et al. Tenofovir gel for the prevention of herpes simplex virus type 2 infection. N. Engl. J. Med. 373, 530-539 (2015).

41. Hladik, F. et al. Mucosal effects of tenofovir 1\% gel. Elife 4, e04525 (2015).

42. Morrow, R.A. \& Friedrich, D. Inaccuracy of certain commercial enzyme immunoassays in diagnosing genital infections with herpes simplex virus types 1 or 2. Am. J. Clin. Pathol 120, 839-844 (2003).

43. Morrow, R.A., Friedrich, D., Meier, A. \& Corey, L. Use of "biokit HSV-2 Rapid Assay" to improve the positive predictive value of Focus HerpeSelect HSV-2 ELISA. BMC Infect. Dis. 5, 84 (2005).

44. John, $M$. et al. Cervicovaginal secretions contribute to innate resistance to herpes simplex virus infection. J. Infect. Dis. 192, 17311740 (2005).

45. Bull, M. etal. Defining blood processing parameters for optimal detection of cryopreserved antigen-specific responses for HIV vaccine trials. J. Immunol. Methods 322, 57-69 (2007).

46. Hosken, N. et al. Diversity of the CD8 + T-cell response to herpes simplex virus type 2 proteins among persons with genital herpes. J. Virol. 80 , 5509-5515 (2006).

47. Posavad, C.M. et al. Detailed characterization of Tcell responses to herpes simplex virus-2 in immune seronegative persons. J. Immunol. 184, 3250-3259 (2010).

48. Jerome, K.R., Huang, M.L., Wald, A., Selke, S. \& Corey, L. Quantitative stability of DNA after extended storage of clinical specimens as determined by real-time PCR. J. Clin. Microbiol. 40, 2609-2611 (2002). 